\title{
Development of a VR Nursing Educational Content
}

\author{
Seoung-Uk Wie ${ }^{1}$ and Hyo-Jin Kim ${ }^{2}$ \\ ${ }^{1}$ Chosun Nursing College, Korea \\ ${ }^{2}$ Donggang University, Korea \\ ${ }^{1}$ wienona@hanmail.net, ${ }^{2}$ kimhyoddol@naver.com
}

\begin{abstract}
The purpose of this study was to develop a virtual reality $(V R)$ educational content for nursing college students to strengthen their capacity to cope with multiple trauma situations. The VR educational content for nursing of patients with multiple trauma was developed based on the ADDIE (Analysis, Design, Development, Implementation, Evaluation). The emergency service was composed of the following process: Patient condition check, preparation for emergency supplies and treatment completion. In the educational content, a visual limit of the existing simulation learning was supplemented. This study has a meaning in that it developed a VR educational content program on emergency service for patients with multiple trauma and assessed possibility and effects of VR education first in Korea.
\end{abstract}

Keywords: Learning flow, Multiple trauma patients, Nursing competence, Nursing knowledge, Patient nursing, VR (Virtual reality) educational content

\section{Introduction}

These days, in national emergency situations, 125,000 patients with severe trauma have been reported in a year, of which 11,000 (that is, 10\%) were dead and as many as 3,500 might have survived if proper early intervention was made[1]. Therefore, medical personnel should make every effort to in advance identify potential risks in multiple trauma situations, prevent and cope with them quickly. For this, they should have organized and extensive clinical knowledge on multiple trauma patients[2].

In emergency situations of patients with multiple trauma, as nurses usually manage and classify patients according to acuity as the first finders, they have to quickly and exactly judge situations and provide emergency service[3]. In these situations, if nurses have confidence in their capacity, they can adapt themselves to environment given and cope with the situations calmly and effectively[4], which has an influence on judgement and nursing capacity required in clinical situations[5][6]. It is very important to nursing students who will provide emergency care as professional medical personnel[7]. However, due to the atmosphere of clinical situations that put an emphasis on safety and rights of patients, nursing college students are faced with a number of limits in applying nursing techniques and knowledge they learn[8]. In particular, as in emergency nursing practices, mistakes in nursing service and judgement have serious influences on convalescence of patients, the limits of practices have to be overcome[9]. Therefore, to enhance nursing competence to quickly and exactly cope with multiple trauma situations, nursing students should have nursing knowledge on patients with severe trauma.

Article history:

Received (January 6, 2019), Review Result (April 9, 2019), Accepted (July 12, 2019) 
Also, we should consider in developing educational methods and media that can enhance confidence in nursing performance and have much learning flow effect.

Most of the previous studies in our country gave a focus on Emergency Medical Service or medical students and used high-fidelity mannequin simulators as study methods. As such simulation-based education provided environment where students were trained in a safe way[10], it could be a more effective alternative than traditional educational methods in traumarelated education[11], but it had a deadly limit that it could not realize specific situations or changes in patient's condition in physical examination that needs visual check in specific situations such as multiple trauma[12]. In considering the limitations of the existing simulation learning program and the advantages of the virtual reality simulation which can be reproduced more realistically and visually, it is suggested that the virtual reality simulation is an appropriate clinical practice education tool that can enhance capability of nursing students to professionally cope with multiple trauma situations..

Therefore, this study developed a VR on nursing of multiple trauma patients for which a multiple trauma situation scenario was applied based on the ADDIE (Analysis, Design, Development, Implementation, Evaluation) as a central development stage of teaching system design, applied it for nursing college students and evaluated its educational possibility and effects. Based on the results, this study was to prepare the base of clinical practice program that can reinforce capability of nursing students and make a contribution to provision of high-quality nursing service. .

\section{Methods}

\subsection{The study progress}

The VR educational content on nursing of patients with multiple trauma was developed based on the ADDIE model (Analysis, Design, Development, Implementation and Evaluation) and consists of the followings: check of patient conditions, preparation of emergency articles, care preparation process and emergency care completion.

\subsubsection{The analysis stage}

In the analysis stage, we analysed requirements of the focus group and interviewed a group of experts. For the requirements analysis, this study interviewed 10 nursing college students who experienced emergency nursing practices in a semi-structured way, and as a result of the analysis, they responded that they were not sure whether they could provide emergency care and make exact judgements on emergency situations only with observation program and most of them suggested that they should receive actual training on multiple trauma situations. As for the expert interview, to analyse nursing capability required to nursing college students for whom a VR educational program was applied, we interviewed 3 emergency nursing professors in a semi-structured way. The results were: the experts selected nursing competence including promotion of health as central of the performance capabilities presented by The International Council of Nurses(ICN 2003); and responsibility, inspection, planning, performance, evaluation and cooperation between experts as basic capabilities relating to the central capability. They suggested that the students should have practical and repetitive training on multiple trauma situations to enhance the capabilities.

\subsubsection{The design stage}


In the design stage, educational goals were designed and contents were made up of based on the results of what was investigated. The goals were to improve nursing knowledge on trauma patients and enhance confidence in nursing performance. The contents were composed of inpatient situations, acuity assesment at the first sight and the 1st investigation result, frequently-complaining symptoms, the KTAS stage, initial vitality signs, case information(outlines of cases, basic information of patients, questions according to systems, and physical examination, examination information, prescription order, and nursing records). This study developed cases of multiple trauma patients that can be classified by KTAS(Korea Triage Acuity Scale) presented by KTAS Committee under the Korean Society of Emergency Medicine into a scenario referring to trauma cases of the Pre-tests provided by the KTAS Committee. In the scenario, a 40-year-old male patient who had fallen from the height of $5 \mathrm{~m}$ was taken to the emergency room by 119 rescue. Also additional prescription and examination results were provided according to flows of multiple trauma situations so that nursing students could cope with changes of patients flexibly.

In addition, as for judgement of patients' conditions in the VR situation, preparation of emergency objects and selection of nursing interventions, we referred to the textbooks of adult nursing program, reflected clinical fields to develop contents of multiple trauma situations, revised and supplemented the contents in consultation with 5 clinical experts $(2$ emergency medicine doctors and 3 nurses who had more than 5 years of career in emergency rooms).

\subsubsection{The development stage}

In this stage, a program was developed and realized. In respect to education contents on multiple trauma situations, development methodology and the simulated clinical situation model were decided through discussion with a web programmer of a VR producer. Also, as for development and manufacturing of a moving platform and control software, a Gear VR and a HTC Vive as interactive VR content systems were used, and in virtual space using 3D modelling, the nurse station and the emergency acuity classification area were simulated through discussion. For the development and realization of the VR education program on nursing of multiple trauma patients, the VR was implemented in $3 \mathrm{D}$ virtual space with the use of the gear VR, the virtual space was examined through head tracking, and UI was manipulated in the direction of the remote control.

\subsubsection{The performance and evaluation stage}

To know whether the learning goals and system of the developed learning program were good for its effective composition and operation, a group of experts consisting of 2 emergency medicine professors and 5 nurses who had more than 5 years of career in emergency service joined in the validity test and evaluation.

The statements on the validity of the contents were as follows: not very suitable; have to be revised as it was not suitable; have to be revised somewhat even though it was suitable and very suitable. Whether learning goals and system were properly composed of was checked and if revision was needed, the experts were asked to write their opinions out. As a result of testing the content validity, content validity index(CVI) was 1.0, which indicated that all the experts evaluated that it was suitable. The content validity index of the learning system ranged from 0.78 to1.0, which indicates that it was suitable.

For the VR contents revised and supplemented via consultation with experts and the content validity test, to in advance find technological and methodological problems, about 10 nurses 
who had experiences of emergency service practice were convenience-sampled and a preliminary implementation was made to them.

The subjects of the preliminary test reviewed the VR progress procedure, acuity classification situations, standards, and performance requirements and then acted according to personal judgement. When their evaluations were analysed through open-ended questions on the multiple trauma patient nursing VR contents, there were positive opinions on the virtual reality and requests for improvements relating to immersion into the virtual reality. Also, they expressed positive opinions on the followings: the VR program would help students have more confidence in their capability in doing actual clinical service and higher academic achievements through the entire curriculum. There were requests for improvements in each item and other specific opinions: As for understanding of the scenario, diverse scenarios and situations that can extend learning flow should be developed, and visual effects should be emphasized when information was provided for judgement of situations. In respect to patients, there were opinions on absence of communication between patients and nurses and lack of changes in patients as the scenario progressed. In respect to the situations, they gave opinions on needs of visual effects and auditorial stimulation in addition to situations given, change in students' view points and transfer. This study finally revised the scenario by reflecting evaluation results and improvements obtained from the scenario, patients, objects and situations.

\subsubsection{The program decision and application}

After experts' evaluation was completed and the program was revised and supplemented through the preliminary implementation, this study developed and realized a VR content program on nursing of multiple trauma patients for nursing college students. The time required to achieve learning goals with the use of the VR content program was about 10 minutes and the time for debriefing of the evaluation results was about 30 minutes. Both the experimental group and the control group were given information on the scenario of multiple trauma situations. The learning process was applied for the experimental group about 30 minutes while the control group was provided for printouts on the multiple trauma situations. The VR program was applied and evaluated in the school VR room and after the application, the students were asked to give self-reported answers on the degree of learning flow, nursing knowledge and confidence in nursing performance.

\section{Results}

\subsection{Development of a VR educational content}

This study developed a VR educational content on multiple trauma patient nursing care for nursing students via the five-step development procedure of the ADDIE model from October 2017 to December 2018. The learning content as an educational medium was based on 'virtual reality' technology that can implement the simulated clinical situation according to the learning objective presented.

\subsubsection{Patient's condition confirmation}

At the onset of the multiple trauma situation, the patient's first impression evaluation information, the patient's chief complaint, and the nursing assessment outcome (incident information, vital signs, pain, physical assessment results) were provided. 


\subsubsection{Equipment confirmation}

The VR environment consisted of equipments and facilities that can be seen in an emergency room: a patient monitoring device, a medication infusion pump, an emergency cart, and defibrillator. The simulation scene for emergency item preparation showed emergency medicine and first aid required in situations of patients with multiple trauma. When the subjects clicked the part related to drugs or treatment, the program showed a pop-up window.

\subsubsection{Priority selection}

After checking the emergency treatment items, the subjects were asked to decide priorities of the items prepared and treatment process. To give the sense of urgency to the subjects, the program had the selected items applied to the patients visually in the VR situation. .

\subsubsection{Completion}

When the subjects applied all the treatment process required for the VR patient, the patient's condition in the VR screen improved and the emergency room treatment was completed. In order to stimulate the subject's recall of nursing multiple trauma situations and to effectively organize what they learned, the program showed them nursing records written over time.

\section{Conclusions}

This study developed the VR contents program for nursing college students on nursing of multiple trauma patients through the 5-stage development procedure of the ADDIE model from October 2017 to December 2018. The learning content program developed based on the virtual reality technology that can realize simulated clinical situations according to learning goals was applied for the nursing college students.

In the educational content, a visual limit of the existing simulation learning was supplemented. This study has a meaning in that it developed a VR educational content program on emergency service for patients with multiple trauma and assessed possibility and effects of VR education first in Korea.

Based on the results, this study offered the following suggestions. First, this study confirmed that knowledge on nursing and nursing confidence were required in nursing situations, but as effective communication with the patients accompanied by the patient nursing situations is also important, further education contents on integrated nursing service capability should be developed, Second, further VR programs relating to diverse patient nursing situations should be developed and repetitive studies to test their effects should be conducted.

\section{References}

[1] Korea Internet\& Security Agency, Survey on the Internet Usage, (2015)

[2] E. Y. Yu, C. K. Yoon, and Y. J. Yang, "The relationship between self-esteem and mental health of college student in some regions," Journal of the Korea Academia-Industrial cooperation Society, vol.13, no.1, pp.274283, (2012) DOI: 10.5762/KAIS.2012.13.1.274

[3] H. J. Song, "A Study on SNS addiction using smart phones," Korean Association of Addiction Crime Review, vol.1, no 2, pp31-49, (2011)

[4] K. H. Hwang, Y. S. Yoo, and O. H. Cho, "Smartphone overuse and upper extremity pain, anxiety, depression, and interpersonal relationships among college students," The Journal of the Korea Contents Association, vol.12, no.2, pp.365-375, (2012) DOI: 10.5392/JKCA.2012.12.10.365 
[5] Raacke J, and Bonds-Raacke J., "My space and facebook: applying the uses and gratifications theory to exploring friend-networking sites," CyberPsychology \& Behavior, vol.11, no.2, pp.169-174, (2008) DOI: 10.1089/cpb.2007.0056

[6] E. B. Weiser, "The functions of Internet use and their social and psychological consequences," Cyberpsychology \& Behavior, vol.4, no.6, pp.723-743, (2001) DOI: 10.1089/109493101753376678

[7] H. S. Choi and J. C. Ha, "A Study on the factors inducing internet addiction of college students," Journal of the Korean Data \& Information Science Society, vol.22, No 2, pp437-448, (2011)

[8] K. H. Seo and S. H. Jo, "An exploratory study on factors related with SNS addiction proneness: Focus on covert narcissism, self-presentational motivation, and sense of alienation," Journal of Korean Psychological Association, vol.18, No 2, pp.239-250, (2013)

[9] S. Schlein, B. Guerney, and L. Stover, "The Interpersonal Relationship Scale, Unpublished doctoral dissertation," Pennsylvania Stata University, Philadelphia, (1971)

[10] I. S. Lee and J. Y. Jo, "Factors Influencing SNS Addiction Tendency among College Students," Journal of The Korean Data Analysis Society, vol.14, no.5, pp.2623-2633, (2012)

[11] S. I. Kim, "The influence on friendships motivated by the use of SNS," M.S. thesis, Kyungpook National University, Deagu, (2014)

[12] Y. Seong, and M. H. Hyun, "The mediating effect of experiential avoidance on the relationship between undergraduate student's motives for using SNS and SNS addiction tendency: Focused on facebook," The Korean journal of stress research, vol.24, no.4, pp.257-263, (2016) DOI: 10.17547/kjsr.2016.24.4.257

\section{Authors}

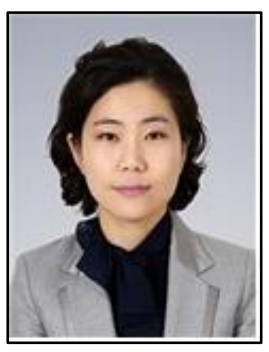

\section{Seoung-Uk, Wie, RN, Ph.D}

Assistant Professor of Nursing a Chosun Nursing College

Tel. +82-62-231-7080

e-mail.wienona@hanmail.net

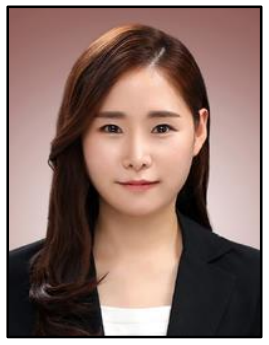

\section{Hyo-Jin, Kim, RN, Ph.D}

Assistant Professor of Nursing a Donggang University

Tel. +82-62-520-2362

e-mail.kimhyoddol@naver.com 